\title{
ESTÉTICA DA VIOLÊNCIA ${ }^{1}$
}

\section{Sucesso e banalização da violência na mídia podem obscurecer a compreensão da realidade e levar a avaliações precipitadas}

Imagens representando situações de extrema violência - física e também moral invadem as telas da TV em todas as horas do dia e da noite na maioria das emissoras. $\mathrm{O}$ hábito, a inércia e uma certa complacência distraída transformam o telespectador em voyeur participante que se diverte.

A interatividade eletrônica vem acrescentar eficácia e aumentar o impacto desta estética da violência que vai se generalizando sobretudo entre os jovens amantes de videoprogramas, de música em altas doses de decibéis e de filmes como Pulp fiction (Tempo de violência), do diretor Quentin Tarantino.

As possibilidades criadas pelas técnicas de realidade virtual fazem da violência a mais promissora das drogas do futuro próximo. A viagem desesperada dos personagens do filme Até o fim do mundo, de Win Wenders, é uma metáfora da força inebriante das imagens e do poder das redes informáticas.

Até mesmo o jornalismo se rende às fórmulas de sucesso da estética da violência e nos brinda todos os dias com doses cada vez maiores de cenas hiper-realistas, nas quais polícia e televisão atuam juntas em caçadas aos bandidos dos morros cariocas ou da periferia paulistana. Aí podemos assistir, ao vivo e em cores, a blitz de policiais reais com detalhes em close da cara do ban- dido que, às vezes, ocupa seu espaço na mídia e até dá entrevista.

"Um imaginário dominado pelo princípio de morte"2, diz o professor Teixeira Coelho referindo-se à televisão brasileira. Princípio de morte que se materializa em imagens fragmentadas, encadeadas em ritmo acelerado, compondo mensagens (ou textos) audiovisuais cada vez mais complexas em termos técnicos (combinação dos efeitos de luz e som) e cada vez mais estandardizadas em termos semânticos (das significações construídas), porque submetidas às exigências técnicas e mercadológicas. $\mathrm{A}$ história do imaginário ocidental é aliás marcada pela morte: o cristianismo é a religião que adora o deus morto (Nietzche).

A importância destas mensagens difundidas em escala planetária para um público jovem, considerado como consumidor potencial, é enorme ${ }^{3}$. O discurso fragmentado, o mosaico das "culturas híbridas"4 típico da pós-modernidade, o espelho deformante da mídia audiovisual, tudo leva à difusão de uma postura narcísica entre as tribos de jovens que se deleitam - real ou virtualmente

\section{A AUTORA}

\section{Maria Luiza Belloni}

Coordenadora do Laboratório de Novas Tecnologias, Centro de Ciências da Educação, Universidade Federal de Santa Catarina.

1. Comunicação apresentada na mesa redonda Educaçâo para a mídia: a ética e a estética. $8^{\circ}$ EDIPE, Florianópolis, maio, 1996.

2. TEIXEIRA COELHO. O imaginário de morte. In: NOVAES, Adauto (org.). Rede imaginária: televisão e democracia. São Paulo: Cia. das Letras, 1991.

3. Ver por exemplo; BELLONI, M. L. A mundialização da cultura. Sociedade e Estado. Brasília: EdUnB, n.1-2, 1994.

4. CANCLINI, Nestor Garcia. Culturas híbridas: estratégias para entrar e sair da modernidade. São Paulo: EDUSP, 1997. 
- com a festa constante do consumo, realizando agora o que Marcuse previa nos anos 60: as "relações libidinosas com a mercadoria"s. Nada disso estimula a reflexão ou ajuda na construção da cidadania, muito pelo contrário.

A estética da violência é uma das fórmulas de maior sucesso da TV e do cinema pós-TV. A repetição ad infinitum dessas fórmulas leva à padronização globalizada dos diferentes gêneros televisuais, tanto do ponto de vista ético (dos significados valorativos) quanto do ponto de vista estético (da composição técnica das narrativas).

O sucesso da violência como estilo estético e como símbolo ou metáfora do mundo contemporâneo parece incontestável: os números de audiência e bilheteria o comprovam. Em termos estéticos, a repetição e o uso abusivo destas figuras de estilo tendem a banalizar o efeito no espectador, que acaba achando engraçadas as cenas de terror. O que não diminui o sucesso e, de certa forma, inocenta a violência.

Do ponto de vista ético, o exemplo da violência real e fictícia, representada e repetida sem cessar na TV nossa de cada dia, acaba construindo uma realidade (virtual e longínqua) cheia de guerras, explosões, brigas e mau-caratismo que obscurece a compreensão da realidade imediata (material, de fato), cujos problemas e situações concretas demandam nossa atenção e atuação.

A visão de um mundo perigoso lá fora, lá longe, nos remete à falsa segurança e felicidade de nosso mundo, consolando-nos de nossas misérias cotidianas e dificultando o exercício da autonomia de cada um de nós como sujeitos de nossa história.

A estética da violência constrói e generaliza significados que banalizam e naturalizam a violência, legitimando o uso de meios violentos para se alcançar fins nobres, efeito que muitas pesquisas têm mostrado como freqüente entre crianças e adolescentes ${ }^{6}$.

A mídia constrói e difunde uma visão maniqueísta do mundo que absolutiza o bem e o mal, mesmo quando os apresenta com sinal invertido, como é o caso de Leonardo Pareja, o jovem bandido-herói, que teve seu momento de celebridade e glória em abril de 1996.

\section{HERÓI DO DIA}

"Charles Anjo Quarenta e Cinco Defensor dos fracos e oprimidos Robin Hood dos pobres Rei da malandragem Um homem de muita coragem... Só porque um dia Charles marcou bobeira E foi parar numa colonia penal."

Jorge Benjor

Capa de $V e j a 7$ : Rapaz de boné e camiseta branca olhando de cima para baixo, dedo em riste, expressão de firmeza irônica no rosto. Conotação: líder comanda, dá as ordens. Do alto do muro de um presídio no Estado de Goiás, Leonardo Pareja, 22 anos, condenado por roubo e seqüestro, comanda um motim de presos que se tornou um espetáculo midiático, no qual os personagens principais vivem dramas reais com papéis trocados: os bandidos são os heróis e a polícia faz papel de boba.

A foto de capa mostra um jovem branco, um brasileiro comum, que podemos encontrar em qualquer esquina ou nos bancos

5. MARCUSE, H. A ideologia da sociedade industrial. Rio de Janeiro: Jorge Zahar, 1969.

6. BELLONI, M. L. O herói de mentirinha e a violência de verdade. Revista Humanidades. Brasilia: EdUnB, n.19, 1988.

7. VEJA. São Paulo: Abril, 10 abr. 1996. Capa. 
da escola ou da universidade. Não parece tenso, ao contrário, parece calmo e vislumbra-se uma luz irônica em seus olhos e meio sorriso. Parece estar se divertindo com a situação. Leonardo Pareja, herói de poucas horas (na verdade ele vai fazer durar alguns dias sua celebridade), dá as cartas e está ganhando o jogo: domina a situação que é da mais alta dramaticidade. Em face desse tipo de jogo, a polícia, que só sabe ser truculenta, não tendo ordem para atacar e matar, fica inerte, inepta, sem reação.

O título da reportagem de capa da Veja pretende resumir a situação: $O$ bandido $e$ os otários. Como Leonardo Pareja fez a polícia de boba. Otários evidentemente somos todos nós, cidadãos contribuintes que sustentamos um Estado caro e falido que não consegue assegurar nem mesmo os serviços básicos de segurança. Otários são também os membros da polícia e da Justiça goianas, cuja cúpula visitava a penitenciária quando foi seqüestrada pelos presos amotinados. Ainda mais otários são os membros do Governo do Estado, negociadores inexperientes e sem competência, expostos ao ridículo em rede nacional e mesmo internacional $(C N N$, por exemplo) por um garoto de 22 anos.

Herói incontestável deste episódio, Leonardo Pareja soube atrair para si as atenções, os refletores e a simpatia do público. Líder nato, inteligente e esperto, Leonardo não começou o motim, mas assumiu naturalmente o comando, funcionando ao mesmo tempo como chefe organizador competente e como negociador experimentado, intermediário entre os presos amotinados e as mais altas autoridades do governo estadual.

Carismático, ele conquistou corações e mentes de muitos jovens brasileiros, re- presentados por um dos reféns, o estudante de Direito Aldo Sabino, de 23 anos, que se ofereceu como escudo para o bandido escapar do cerco policial.

Egocêntrico e mimado, típico da geração narcisista e audiovisual, ele exigiu bolo com velinhas para comemorar seu aniversário. Exibicionista experimentado de muitas horas de telinha global, ele armou e comandou o circo devidamente espetacularizado pela mídia, onde ele era o mestre de cerimônias e a estrela principal, e as autoridades apareciam como palhaços. Jogou futebol, tocou violão, apagou as velinhas do bolo e, qual astronauta que conquista a Lua, subiu na caixa d'água do presídio e lá plantou a bandeira nacional.

\section{FRUTO DA MÍDIA}

Leonardo Pareja já tinha mostrado estas qualidades midiáticas no ano anterior quando, depois de brincar de esconder (fugindo e dando entrevistas a rádios locais) com a polícia de três Estados brasileiros durante quarenta dias, entregou-se a uma repórter da TV Globo. Assíduo freqüentador da telinha, portanto conhecedor de seus mitos, ele confessa que gosta de ser famoso ("Quem não gosta? eu adoro!"), considera-se o herói dos oprimidos e se identifica com Robin Hood. ("Eu sou um herói dos presos, gente que foi humilhada e maltratada pela polícia").

Fruto típico da mídia, ele parece conhecer os truques do espetáculo: aprendeu nos filmes e seriados americanos como manipular e dominar situações de perigo e como usar a mídia a seu favor. Daria um ótimo conselheiro de marketing político ${ }^{8}$.

8. Leonardo Pareja foi assassinado pelos companheiros na prisão em 09/12/96. Em seu velório houve tumulto quando a polícia apreendeu a bandeira nacional com a qual os amigos tinham coberto o caixão, numa homenagem àquele que eles consideram um herói. 


\section{RUPTURA DO PACTO SOCIAL}

Analisando o crescimento dos índices de criminalidade no Brasil em 1984, o brilhante psicanalista Hélio Pellegrino explicava os fundamentos da sociedade a partir de um pacto social, baseado no pacto edípico que faz a criança reprimir sua agressividade contra o pai para assegurar seu afeto e proteção. Este pacto, que a psicanálise freudiana chama de Lei da Cultura, é o acordo pelo qual a criança se torna membro da sociedade humana, compreende e aceita suas imposições. $\mathrm{O}$ trabalho, exigência da sociedade a todos os seus membros, significa um sacrifício que cada indivíduo tem que fazer em troca dos benefícios da vida em sociedade, inclusive a segurança, mas principalmente $o$ trabalho.

Quando a sociedade se revela incapaz de proporcionar trabalho para a maioria dos indivíduos, há uma ruptura deste pacto social. "Esta ruptura, fraudadora e conspurcadora da dignidade humana, pode levar ao desespero, à cólera, à revolta. $\mathrm{O}$ trabalhador tenderá a repelir o pacto social e os sacrifícios que ele exige. (...) Este efeito se tornará tanto mais provável quanto mais existir numa sociedade determinada, além do desrespeito ao trabalho, um clima de apodrecimento dos valores que poderiam cimentar a adesão social"9.

Tal análise, denúncia da violência e da criminalidade do início dos anos 80 , mostra-se cada vez mais apropriada. Naqueles anos assistíamos à denúncia ininterrupta de escândalos de corrupção, envolvendo funcionários dos altos escalões do governo (Figueiredo), levada a sério por uma imprensa recém libertada da censura.
Desde então, não apenas os índices de criminalidade e de violência urbana têm aumentado assustadoramente, como a quantidade e a magnitude dos crimes ditos de colarinho branco alcançaram níveis inimaginados.

No campo político a ruptura do pacto social manifesta-se como descrença na política, crise da representação e, por conseguinte, ausência de legitimidade do Estado e do governo, o que põe em risco a estabilidade política e a democracia ${ }^{10}$.

No campo social, esta ruptura se revela no crescimento e generalização de comportamentos anti-sociais e da violência. Quando a crise inclui fatos, escândalos que revelam corrupção e decadência entre as elites, a ruptura do padrão social pode ter consequiências sociais catastróficas: sequiestros, saques, homicídios, estupros, incestos, linchamentos e violência de massa - como as dos estádios de futebol -, tendem a se tornar comuns. Violências de todo o tipo passam a ter livre curso na conduta.

\section{AÇÃO DA MÍDIA}

\section{"Quem lê tanta notícia?" \\ Caetano Veloso, 1968}

Difundindo para todos os públicos, com a mesma abordagem sensacionalista, os privilégios e ações das classes dominantes e as ocorrências violentas, a ação da mídia pode ter um efeito generalizador e provocar uma espécie de naturalização da violência como uma volta à barbárie. Como exigir do povo pressionado pela miséria, sem dignidade nem cidadania, que cumpra 
sua parte do pacto (sendo ordeiro e trabalhador) e que assista impassível aos desmandos das elites que invadem suas vidas, através do espetáculo da mídia?

Tentando compreender o imaginário constituído pelas imagens da TV, Teixeira Coelho identifica alguns aspectos fundamentais: o maniqueísmo típico do mundo pré-moderno, coabitando com as mais avançadas técnicas televisuais, e a representação contínua de um mundo violento. Segundo este autor, a TV no Brasil "usa a violência como forma de controle social. Atemoriza a sociedade para que o poder apareça como recurso salvador"'I!.

Da mesma forma que, segundo Adorno e Horkheimer, o Pato Donald apanha o tempo todo para que os espectadores se habituem com seu próprio infortúnio, a TV nos mostra um mundo perigoso para que nos confortemos com a segurança do nosso sofá e aceitemos sem reservas a necessidade do poder, de um sistema que nos proteja ${ }^{12}$.

Quando este sistema falha, como acontece tantas vezes, todo o sistema de valores da sociedade fica abalado. Os bandidos se tornam heróis, o bem e o mal se confundem. Vence então a cultura do levar vantagem, a lei do mais forte e do mais esperto.

\section{POLÍTICA E VIOLÊNCIA}

A espetacularização da política e da violência é uma marca de grande visibilidade da história brasileira, na qual corrupção, cooptação e violência sempre foram as armas usadas pelas elites na manutenção do sistema de dominação.
No Brasil, política e violência sempre formaram uma associação perversa, agora multiplicada ao infinito pelas mídias, como num jogo de espelhos, onde se movem heróis e bandidos, modelos admirados por crianças, adolescentes e adultos, personagens com alto poder de identificação, com grande carisma que a mídia constrói e amplifica.

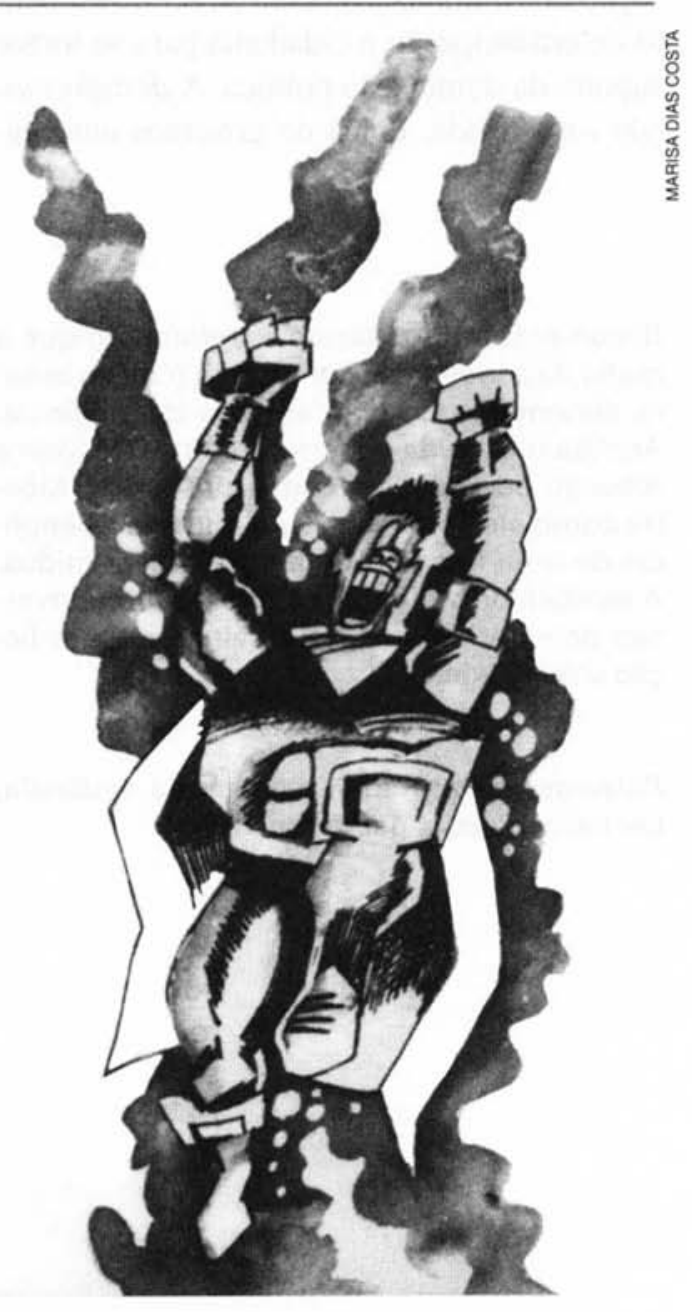


No Brasil contemporâneo, a mise en scène (encenação) do espetáculo político está baseada em técnicas sofisticadas de comunicação política, montada expressamente para a publicização dos negócios públicos. Este espetáculo cria uma transferência aparente que esconde ou tenta disfarçar a condução da real política.

O princípio da transparência (a publicização dos iluministas) deixa de ser instrumento de emancipação e cidadania para se tornar suporte da dominação política. A desinformação organizada, típica de governos autoritá-

Resumo: $\mathrm{O}$ artigo discute o tratamento que a mídia dá à violência, compondo o que a autora denominou de uma estética da violência. Analisa o caso da cobertura da revista Veja à rebelião liderada por Leonardo Pareja. Mostra como ele soube utilizar a mídia em benefício de uma imagem de herói dos oprimidos. A estética da violência colabora para a inversão de valores e para o amálgama entre ficção e realidade.

Palavras-chave: midia, estética da violência, Leonardo Pareja, pacto social rios e sistemas totalitários, invade, através da mídia, todos os campos da vida social.

O sujeito, saturado de notícia e de violência, no jornal como na ficção, acaba por fazer o amálgama entre o movimento sem terra da realidade com o Rei do gado da novela das oito, onde tudo será resolvido pelo melhor, sem nossa intervenção. Na novela, a reforma agrária já foi devidamente exorcizada pelo Senador Caxias, um personagem com poucos pontos no Ibope, um perdedor digno e patético com quem ninguém (ou quase) quer se parecer.

Abstract: The article discusses the treatment the media gives violence, composing what the author denominated as violence esthetics. The author analyses the case of Veja magazine's coverage of the rebellion lead by prisoner Leonardo Pareja. It is shown how this prisoner was able do use the media to benefit from an image of a hero of the oppressed. Violence esthetics collaborates to the inversion of values and to the mixture between fiction and reality.

Key words: media, violence esthetics, Leonardo Pareja, social pact 